This item was submitted to Loughborough's Research Repository by the author.

Items in Figshare are protected by copyright, with all rights reserved, unless otherwise indicated.

\title{
The politics of belonging in the Indigenous North
}

\section{PLEASE CITE THE PUBLISHED VERSION}

https://www.routledge.com/Knowing-from-the-Indigenous-North-Sami-Approaches-to-History-Politics/EriksenValkonen-Valkonen/p/book/9780415790734

\section{PUBLISHER}

Routledge

VERSION

AM (Accepted Manuscript)

\section{PUBLISHER STATEMENT}

This is an Accepted Manuscript of a book chapter published by Routledge in Knowing from the Indigenous North: Sami Approaches to History, Politics and Belonging on 2 October 2018, available online: http://www.routledge.com/9780415790734.

\section{LICENCE}

CC BY-NC-ND 4.0

\section{REPOSITORY RECORD}

Skey, Michael. 2018. "The Politics of Belonging in the Indigenous North". figshare. https://hdl.handle.net/2134/27057. 


\section{The politics of belonging in the Indigenous North}

\section{Michael Skey, Department of Social Sciences, Loughborough University}

It's probably worth noting at the outset that while I have learnt a great deal from working with the authors of this collection, I am not an expert on Sami culture, history or politics. Therefore, this comment piece will be used to provide a number of general reflections on the challenges of studying groupness. In other words, trying to understand the 'process through which persons sharing some categorical attribute come to share definitions of their predicament, understandings of their interest and a readiness to take collective action' (Brubaker \& Cooper, 2000: 9), without reducing them to caricatures and/or reifying their activities. In particular, it will be argued that approaches that emphasis belonging and the politics of belonging are better equipped to study such issues, notably as they relate to non-Western contexts and people that have, until recently, remained on the margins of both society and social scientific theorising. In short, I will be using some of the arguments made in chapters across this collection to highlight and evidence the salience of the analytical framework being proposed.

\section{"Identity rules - and rules out" $\mathrm{i}$}

Valkonen and Ruuska have already called into question the utility of the concept of identity in their chapter examining the changing practice of reindeer herding among the Sami. They follow in the footsteps of a number of other scholars (Handler, 1996, Brubaker \& Cooper, 2000, Malasevic, 2006) and it's perhaps worth briefly revisiting some of their criticisms. For Sinisa Malesevic the primary problem with identity can be traced back to its initial use as a conceptual tool in maths and logic, where it is used to indicate either absolute or zero difference. He notes that these strong and weak uses of identity can also be seen in use across the social sciences where identity is either generative of action, fixed and bounded across space/time or, alternatively, fluid and formed by action. Put simply, identity is being made to do so much analytical work that it becomes either everything 
(explaining myriad social and political processes, carving the social world into bounded groups, flattening out people's experiences and motivations) or nothing (as people shift between identities according to their own needs and desires). If the strong version of identity is all encompassing and the weak one doesn't allow us to get to grips with the relative stability of some social formations, how should we proceed? Valkonen \& Ruuska argue that we should start by listening to people, to how they make sense of the world, to how they label their social relationships, and then see whether, when and for what purpose a term such as 'identity' is used. This type of emic perspective is, of course, a useful starting place. But it perhaps neglects, or at least downplays, the wider social structures that enable certain pronouncements or understandings of a given situation to hold good. In other words, we need an approach that is more relational, that is able to connect the individual, the inter-subjective and the institutional (May, 2011) and this is where the recent writing around belonging, and the politics of belonging, may be particularly productive.

\section{Belonging}

Nira Yuval-Davis (2011) has drawn a useful distinction between belonging and the politics of belonging and I plan to discuss each concept in turn, first in more general terms and then in relation to some of the insights from chapters in this collection. Broadly speaking, belonging has been defined as emotional attachment, feeling comfortable, secure or 'at home' (Yuval Davis, 2006: 197) and 'being at ease with oneself and one's surroundings' (May, 2011: 368). While these might seem somewhat nebulous, psychologists have long argued that belonging is a fundamental 'human need' (Baumeister \& Leary, 1995).

In trying to move beyond such general claims, Marco Antonsich (2010) has sought to provide a more coherent analytical framework for the study of belonging, identifying five factors that can help generate these types of attachment or feelings, autobiographical, relational, cultural, economic and legal. The first primarily refer to individual experiences and memories, notably with regard to growing up, which are themselves tied to wider social relations. These would include both intimate 
relations with family and close friends but also the wider networks that people inhabit and provide an ongoing sense of continuity and consistency in their lives. Cultural belonging is often associated with language but also refers to the range of practices, norms and values that enable individuals to successfully orientate their actions towards others, and, in the process, get things done in a relatively smooth manner. Economic factors are important in enabling people to secure material goods for themselves and their loved ones and in often enabling access to wider social and political institutions. Finally, legal factors, such as citizenship rights, allow people to access key social resources, notably those provided by the state, and may offer some degree of protection, and recognition, by powerful institutional actors. The salience of these factors will, of course, vary depending on both the individual context and the type of belonging that we are referring to. And, herein, lies one of the main advantages of the concept. While identity struggles to deal with complexity, grounded as it is in an all or nothing framework, belonging encourages us to think in multidimensional terms from the outset. People can (feel they) belong to places, organisations and groups and, in addition, can articulate a sense of belonging in relation to situations, practices and material objects. Belonging is also part of a process rather than a 'thing' as in the case of identity. It needs to be worked at and while belonging can become taken-for-granted, it always involves an inter-subjective dimension - one cannot belong without the assent of others (much more of which later).

In the case of the Sami, we have seen how a sense of belonging is expressed in relation to particular practices (singing, herding, crafting), material objects (Harlin, this collection), temporal rhythms (Lehtola, this collection), forms of language (Valkonen, this collection) and places (Tervaniemi and Magga, this collection). In the following section, I want to discuss a few examples of these in a little more detail.

\section{The Sami and belonging}


While it doesn't directly address the concept directly, Valkonen and Ruuska's chapter, and the interview data on which it is based, seems to offer a very useful illustration of two of the factors that underpin belonging; autobiography and relations. In discussing their experiences of reindeer herding, and the impact that the snowmobile has had on these activities, the participants not only demonstrate how their own sense of self is tied to a particular landscape but also their ability to master certain aspects of it. What's particularly telling about these exchanges is the very taken-forgranted ways in which these people locate themselves in both the natural environment and the wider social networks that include human and non-human actors as well as key material objects. There is no talk of identity but their sense of comfort and expertise is palpable, they belong in this environment without question.

This sense of local belonging to places, people and practices is articulated across many of the chapters, another good example being Harlin's discussion of duodji. According to Harlin, duodji is 'actively practised by producing and using handicrafts that bind people to the norms of their family and area' (this collection). However, notwithstanding the significance of attending to local or perhaps regional forms of belonging (Tervaniemi and Magga, this collection) in relation to indigenous groups, such as the Sami, there is always a danger of reducing 'them' to a series of caricatures about living with nature (Valkonen \& Valkonen, 2014) or being tied to local traditions like some 'primitive and exotic relic' (Nykänen, this collection).

This is where the multi-dimensionality of the concept of belonging again comes to the fore, focusing on people with a range of solidarities and feelings of affinity rather than the singular, unified subjects posited by so many of the debates around identity (May, 2011: 8). This is beautifully demonstrated in an extract from Nykänen's chapter on the work of the Sami activist, journalist and artist, Nils-Aslak Valkeapää. In discussing Valkeapää’s connections with indigenous groups in North America, it is argued that a shared sense of belonging comes not only through political activism (struggling against a majority culture and experiencess of dispossession and marginalization) but also 
through "the feelings that the similarity of life across the Arctic arouses", including the environment, material objects and cultural practices (Nykänen, this collection). For instance Valkeapää's poem Terveisiä Lapista includes the following lines;

\author{
[...]Lávvu poles against the sky \\ and the moon peeping into the tepee \\ So familiar \\ so strange
}

this life

have I been here before

The drums beat with the rhythm of the heart

Towards the night the Indian yoiks sound

Even while dreaming I hear the yoiking

the drum beats

and all this

so familiar

have I been

here before ${ }^{1}$

Through the lens of identity, these beautiful stanzas might be placed in the box marked 'indigenous' and used to posit a bounded, all-encompassing group who are primarily defined by their sameness. Alternatively, the lens of belonging might first acknowledge that various Arctic peoples share similar attachments to the land, produce recognisable artefacts and cultural practices and are also dealing with some of the same socio-economic and political challenges. At the individual level, Valkeapää's

\footnotetext{
${ }^{1}$ Valkeapää 1994; Valkeapää 1981, 39.
} 
sense of comfort is noteworthy but at the same time we also get a sense of disorientation , 'so familiar, so strange', an idea that is best explicated with regard to a more processual model. At this moment, Valkeapää feels kinship with his hosts but how might this play out in the future? Is it a temporary moment of recognition or something that might form the basis for long-standing alliances? In this case, it is the latter, Valkeapää commits his feelings to paper and emphasizes, in interviews and through his activism, that he feels part of a wider collective and that these connections can be used to bolster the status of the Sami.

At the same time, if we move to the institutional level, the challenges faced by these Northern peoples are related but not the same. For one, they are operating within different legal frameworks, enforced by a state that is the outcome of notably different historical forces. The US and Canadian government has, over the years, adopted different strategies towards indigenous groups - some punitive, some paternalistic - compared with the Scandinavian states, which have tended to be more paternalistic. Therefore, the flattening out of historical, and other, differences that identity demands, doesn't take us very far if we want to take seriously both the connections, but also the disjunctures, between these 'indigenous groups'. In the next section, I will look to pick up this argument again, having first discussed in more general terms the politics of belonging.

\section{The politics of belonging}

As we noted briefly above, attempts to develop and secure a sense of belonging must always be understand as relational (May, 2011). Any individual is, of course, able to make a claim about the extent to which they feel they belong to this or that group, place or situation. Whether such claims are recognised is an entirely different matter that centres on wider structures of power. There are two key points to make here. First, claims to belong are not simply asserted but articulated and negotiated in relation to other social actors and institutional arrangements. Second, we cannot reduce such processes to the same 'ontological level' (Yuval-Davis, 2006: 202). 
If we do treat such claims, and the responses to them, as broadly equivalent, we miss out on understanding the varying importance and consequences of being categorised (or identifying oneself or others) as; male, black, a Muslim, Swedish or transgender, in a given social setting.

'By recognising that some groups may be better able than others to make their categorisations stick we give greater theoretical centrality to relations of domination and subordination' (Donnan \& Wilson, 1999: 25), as well as the institutional structures that make them hold good.

For example, being identified as an undocumented Mexican on the US border is obviously very different from claiming to be a Manchester United fan at a meeting of Liverpool supporters. Those who follow different football teams may argue, and sometimes resort to fight each other, but the consequences of these disputes are not in the same league. Moreover, US immigration officers are more able to justify and enforce their categorisations of 'other' people as they are backed by an extraordinarily powerful institutional order, the US state. What also should be acknowledged is the extent to which being able to make such claims stick (and being recognised, in this way) matters, both in terms of individual agency, as a marker of social status and belonging and in securing access to key material resources. After all, there is a strong link between belonging and entitlement so that saying 'I belong more than you' often means 'I'm entitled to more than you'. As a result, we must pay particular attention to the status of those who define the conditions of belonging, the benefits that flow from such a privileged position as well as the processes by which it is sustained.

In the contemporary era, the growing movement of people, alongside the raised profile of international rights frameworks, means that more established groups are being forced to justify their own dominant status and the benefits that flow from it. A central plank of this strategy has been claims to indigenousness, or 'the idea this is 'our' place and that 'we' deserve to be in control' 
(Kaufman 2004a: 2). Moreover, the outcome of struggles over economic, political and symbolic resources often hinge on the validity of such claims.

As I have argued in previous work $(2011,2013)$, one way of analysing these claims is by thinking about the hierarchies of belonging that operate in a given social setting. My own research has focused on the nation, and has drawn extensively on Ghassan Hage's (1998) concept of national cultural capital. Using Bourdieu's concept of cultural capital as a starting point, Hage argues that, 'nationality can be understood as the sum of accumulated nationally sanctioned and valued social and physical cultural styles and dispositions' (1998: 53). In this way, some people within the nation are perceived to be and treated as if they are 'more (or less) national than others', because they possess particular characteristics (skin colour, accent) and/or competencies (knowledge, practical skills, tastes) (ibid: 52). Hage's model is useful, and can be expanded beyond national frameworks, because it addresses questions of power and change. In other words, it foregrounds the types of resources that people utilize, and struggle over, in order to define (national) belonging, as well as the idea that one can accumulate and, of course, lose such capital. In the former case, power differentials matter not only in terms of inter-group struggles but also those taking place within each group. What also needs to be acknowledged, and will remain the primary focus for the rest of this chapter, is the privileged access to key material and psychological resources claimed by 'those ... who are ... recognized as ... legitimate' (my emphasis, Wimmer 2004: 44). In trying to apply some of the arguments to the Sami case, it may be worthwhile, thinking about how the politics of belonging - or the 'dirty work of boundary maintenance' (Crowley, 1999: 15) - operates on a number of different levels; the local, the national and the global, and how changes in at one level can have profound impacts on another.

\section{The politics of Sami belonging}


In her chapter, Sanna Valkonen offers us an excellent example of the different types of resources that are used in struggles over claims to local belonging as well as how these shift over time in relation to changing social and political circumstances at the national and international level. First, she notes how up until relatively recently defining the Sami was relatively unproblematic, being mainly tied to language use and familial ties. In the former case, language became the first 'official' marker of Sami culture after the ruling of the Committee for Sami Affairs in 1952. In the latter, 'recognition' comes from being involved in more informal networks or social relations as individuals are defined by their 'ties to recognised Sami families' (my emphasis, Valkonen, this collection). Referring back to Antonsich's (2010) conceptual framework, in this context it is cultural and relational forms of belonging that matter the most. Moreover, these examples not only emphasizes the inter-subjective element of all claims to belonging but also the strong links between belonging and recognition, whether official or vernacular.

However, as Valkonen then goes on to argue, changing socio-political circumstances, both in Finland and beyond, have generated further debate "over who has the right to be registered on the electoral roll of the Sámi Parliament, how Indigenous people should be defined in Finland and who should be granted Indigenous rights in the country" (Valkonen, this collection). Of particular significance are the status of the so-called 'Neo-Lapps' whose claims to indigeneity are based on a long-standing presence in the region, which is demonstrated through tax records. In this instance, more of an emphasis is placed on a legally-defined, as well as cultural, form of belonging (Antonsich, 2010). What is also of particular interest, here, is not only how different markers are used to claim belonging but also how these claims develop in relation to changing attitudes towards the Sami in a national context and indigenous groups as a whole within a wider international context. For instance, it seems that contests over who counts as Sami begin to emerge as indigenous groups started to be recognised as having a special status at both the national and international level. At the national level, legislation was enacted to recognise the Sami's unique culture and ancestry and their 
status as an indigenous people who have the right to special protection (Valkonen, Valkonen and Koivurova. 2016). Now, this 'protection' may be somewhat limited in terms of real concrete benefits, but it needs to be compared with those, sometimes brutal, government programmes which emphasised paternalistic forms of 'integration'.

Likewise, this shift at the national level took place against a backdrop of wider international legislature which was again designed to, at least, acknowledge previous iniquities (Oldham and Frank, 2008). For instance, as Gausset and colleagues write, "the United Nations Permanent Forum on Indigenous Issues, the United Nations Declaration on the Rights of Indigenous Peoples, references to indigenous peoples in diverse UN treaties, the International Decade(s) of the World's Indigenous Peoples, are all presented as attempts to take into consideration their problems and redress past wrongs" (Gausset et al, 2011: 135).

Now, of course, that doesn't mean that decades or even centuries of marginalisation and discrimination are simply wiped out, far from it. Many of these legislature frameworks have yet to be ratified and those that are, are often poorly enforced (Oldham \& Frank, 2008). However, with the growing visibility of the debates over the status of indigenous groups, combined with some national and global efforts to protect their culture, habitats and traditions, we can see how a previously stigmatised group becomes (in, however, limited a way) viewed as 'special'. As well as this shift in status, some other tangible benefits (again, often very limited) do begin to flow to such groups. For instance, the Sami have been granted a degree of cultural and political autonomy since the mid1990's (Valkonen, Valkonen and Koivurova. 2016).

This means, most obviously, that there is a growing value in being seen as Sami, in a way that wasn't relevant two decades before. In other words, being defined as Sami now offers access to both ontological and material benefits and demonstrates the ways in which particular forms of, what we might want to call, ethnic cultural capital come to the fore as a result of changing institutional attitudes and legislation at the state and international level. As Valkonen (this collection) has 
argued, when the Lapp movement started to rise in the 1990's, the question was very much about the material benefits that being defined as indigenous was seen to bring to those who were 'allowed' on the electoral roll. Subsequently, those involved have placed much more emphasis on their ontological status, in other words, having their historical roots and traditional livelihoods in the region recognised.

To some this might sound rather crude and instrumental, but as Richard Jenkins has pithily observed, collectivities must offer something to individual members otherwise what would be the point in investing time and effort in them (2002: 22). As a result, these types of struggles need to be carefully contextualised, and theorised, if we are to understand people's motivations and the value of particular forms of (and claims to) belonging. If autonomy and some degree of power are granted to the Sami, then there is a value in being part of this group and those excluded from traditional definitions of Sami culture (language and kinship ties) may therefore be encouraged to think of other ways of making claims to indigeneity.

\section{Conclusion}

This piece has looked to apply insights from the literature on belonging and the politics of belonging to the case of the Sami. Following Probyn, it has argued that belonging;

“captures more accurately the desire for some sort of attachment, be it to other people, places, or modes of being, and the ways in which individuals and groups are caught within wanting to belong, wanting to become, a process that is fuelled by yearning rather than the positing of identity as a stable state” (Probyn, 1996: 19)

It has also used Antonsich’s (2010) conceptual framework to identify the key markers of belonging; autobiographical, relational, cultural, economic and legal and, above all, to note when and how particular markers become privileged and to what ends. Such an approach 
emphasises the absolute importance of attending to relations of power and domination when investigating struggles over belonging and recognition as well as the benefits that flow to those who are (better) able to define the conditions of belonging (Skey, 2013).

In the Sami case, it has been noted that cultural and, in particular, relational forms of belonging were key in defining Sami'ness notably during early attempts to secure political recognition, and some degree of autonomy, from the Finnish state. Subsequently, the picture has become much more complicated as members of what has been labelled, the Neo-Lapp movement, have challenged the established definition of belonging in the Artic North, not to mention the official policy of both the Sami and Finnish parliaments (Valkonen et al, 2016), with particular reference to a legal marker of belonging, historical tax records.

These struggles also offer a very good demonstration of the extent to which local forms of belonging are shaped by wider shifts and social relations at the national and international level. In looking to assert their own status as an indigenous group that should be recognised for its own unique culture, traditions and social organisations (not to mention the years of marginalisation and suffering it has experienced) the Sami have built important networks with other groups in the Arctic region and beyond. The work of these trans-national movements, alongside international organisations, has slowly begun to shift perceptions of indigenous groups and many states have responded, offering (often limited) forms of political and cultural autonomy. Paradoxically, these forms of recognition for the 'special' status of indigenous groups have, in some cases, complicated the issue as alternative claims to indigeneity emerge and the question of who belongs becomes ever more politicised. In the Finnish case, this has meant that "the Finnish state has frozen almost all legislative 
improvements relating to the Sámi’s situation because the question of who the Sámi ... are has become too unclear” (Valkonen \& Valkonen, forthcoming).

Therefore, in looking to study such complex historical processes, it is imperative that we attend not only to the value of being recognised as belonging in a given context or situation but also how the ongoing struggles over who really belongs - the politics of belonging - are shaped by wider institutional forces and structures, at the local, national and international level.

\section{Bibliography}

Antonsich, M. (2010). Searching for belonging-an analytical framework. Geography Compass, 4(6), 644-659.

Brubaker, R., \& Cooper, F. (2000). Beyond "identity". Theory and society, 29(1), 1-47.

Crowley, J. (1999). The politics of belonging: Some theoretical considerations. In A. Geddes and A. Favell (eds) The politics of belonging: Migrants and minorities in contemporary Europe. Aldershot: Ashgate 15-41

Donnan, H., \& Wilson, T. (1999). Borders: Frontiers of identity, nation and state, Oxford: Berg

Gausset, Q., Kenrick, J., \& Gibb, R. (2011). Indigeneity and autochthony: a couple of false twins?. Social Anthropology, 19(2), 135-142.

Hage, G. 1998 White Nation: Fantasies of White Supremacy in a Multi-cultural Society, Annadale: Pluto Press.

Handler, R. (1994). Is 'identity'a useful cross-cultural concept?. Commemorations: The politics of national identity, 27-40. 
Jenkins, R. 2002 'Different Societies, Different Cultures: What are Collectivities?' in S, Malesevic. and M, Haugaard. (eds) Making sense of collectivity: Ethnicity, Nationalism and Globalization. London: Pluto Press

Kaufmann, E. 2004a Introduction: Dominant Ethnicity: From Background to Foreground in E, Kaufmann. (ed). Rethinking Ethnicity: Majority Groups and Dominant Minorities, London: Routledge Malesevic, S. (2006). Identity as ideology: Understanding ethnicity and nationalism. Springer.

May, V. (2011). Self, belonging and social change. Sociology, 45(3), 363-378.

Oldham, P., \& Frank, M. A. (2008). 'We the peoples...': The United Nations Declaration on the Rights of Indigenous Peoples. Anthropology Today, 24(2), 5-9.

Probyn, E. (1996). Outside belongings. Hove: Psychology Press.

Skey, M. 2011 National Belonging and Everyday Life: The Significance of Nationhood in an Uncertain World, Basingstoke: Palgrave

Skey, M. (2013). Why do nations matter? The struggle for belonging and security in an uncertain world. The British journal of sociology, 64(1), 81-98.

Valkonen, J., \& Valkonen, S. (2014). Contesting the Nature Relations of Sámi Culture. Acta Borealia, 31(1), 25-40.

Valkonen, J, Valkonen, S and T. Koivurova. 2016. Groupism and the Politics of Indigeneity: A Case Study on the Sámi Debate in Finland. Ethnicities. First Published June 19, 2016.

Wimmer, A. 2004 'Dominant Ethnicity and Dominant Nationhood' in E. Kaufmann (ed) Rethinking Ethnicity: Majority Groups and Dominant Minorities, London: Routledge.

Yuval-Davis, N. 2006 'Belonging and the Politics of Belonging', Patterns of Prejudice 40(3): 197-214. Yuval-Davis, N. 2011 The Politics of Belonging, London: Sage 
'Valkonen \& Ruuska (this collection) 